\title{
Lobular Capillary Hemangioma of Nasal Cavity
}

\author{
Lt Col S Nair*, Maj A Bahal ${ }^{+}$, Col RS Bhadauria ${ }^{\#}$
}

MJAFI 2008; 64 : 270-271

Key Words : Lobular capillary hemangioma

\section{Introduction}

$\mathrm{N}$ asal lobular capillary hemangioma $(\mathrm{LCH})$ is a benign lesion of unknown etiology, which is commonly associated with pregnancy, oral contraceptives and trauma. Epistaxis and nasal obstruction are the most marked symptoms [1]. The nasal cavity is a rare location for lobular capillary hemangioma. We present a case of lobular capillary hemangioma, which was located on the posterior end of middle turbinate and septum.

\section{Case Report}

A 23 year old serving soldier presented with history of left sided nasal blockage of three years duration and recurrent epistaxis from left nostril for three months. There was no history of trauma, headache, facial pain, prior surgery or nasal packing for epistaxis. On endoscopic examination, a reddish fleshy mass was visualized in the left nasal cavity with attachment to the posterior part of middle turbinate and septum extending posteriorly into the nasopharynx. Posterior rhinoscopic examination showed a lobular mass in the nasopharynx extending from the left choanae.

Radiological examination by computed tomography (CT) scan revealed bilateral chronic sinusitis with septal deviation to right and gave the impression of left sided antrochoanal polyp (Fig.1). Excision of the mass was done endoscopically with the attachments to the middle turbinate and septum removed with cautery. There was minimal bleeding and the postoperative period was uneventful.

Gross examination of the specimen showed a $5 \times 3$ centimeter reddish, fleshy, firm and well encapsulated mass (Fig. 2). The nasal end showed ulceration with necrotic material and the choanal end was well encapsulated and round. Cut section of the mass showed variegated appearance with numerous haemorrhagic areas. Microscopic examination revealed lobular arrangements of capillaries of varying sizes. There was no intercommunicating vascular channel or piling up of endothelial cells. The surrounding stroma showed oedema and mixed chronic inflammatory infiltrate (Fig. 3). The lesion was diagnosed as lobular capillary hemangioma.

\section{Discussion}

Lobular capillary hemangioma ( $\mathrm{LCH})$, which were also known as pyogenic granulomas, are benign polypoid forms of capillary hemangioma primarily occurring on skin and mucous membranes. The term pregnancy tumor has been used to reflect the association with pregnancy [2]. LCH occurs in all ages, but more often in the 3rd decade, and is commoner in females. In the pediatric age group, lobular capillary hemangioma commonly affects males [3]. The gingiva, lips, tongue and buccal mucosa are the most common sites of mucosal lobular capillary hemangioma, but the nasal cavity is a rare site.

The precise mechanism for the development of $\mathrm{LCH}$ is unknown. Traumas, hormonal influences, viral oncogenes, microscopic arteriovenous malformations, the production of angiogenic growth factors and cytogenetic abnormalities have all been postulated to play a role. Lobular Capillary hemangioma cases secondary to postoperative use of nasal packs have been reported $[2,4]$.

Epistaxis and nasal obstruction are the most marked symptoms in cases of nasal lobular capillary hemangioma $[2,4]$. It can be pedunculated or wide based. Its size ranges from several millimetres to centimetres. It is usually found in the anterior part of nasal septum known as the Little's area or Kiesselbach's triangle. Presence in the middle turbinate after nasal packing has been recorded in literature [5]. In our case the attachment was both to the posterior part of middle turbinate and the adjacent septum.

Histologically it is characterized by submucosal vascular proliferation arranged in lobules or clusters composed of central capillaries and smaller ramifying tributaries. There is no intercommunication of vascular spaces or cytological atypia [6]. The differential diagnosis include cavernous hemangioma which occurs less frequently in the nasal cavity, rhinosporidiosis which may

"Graded Specialist (ENT), Command Hospital Air Force, Bangalore 07. ${ }^{+}$Graded Specialist (Pathology), MH Jabalpur, MP 482001. ${ }^{*}$ Senior Advisor (ENT), CH (NC), Udhampur. 


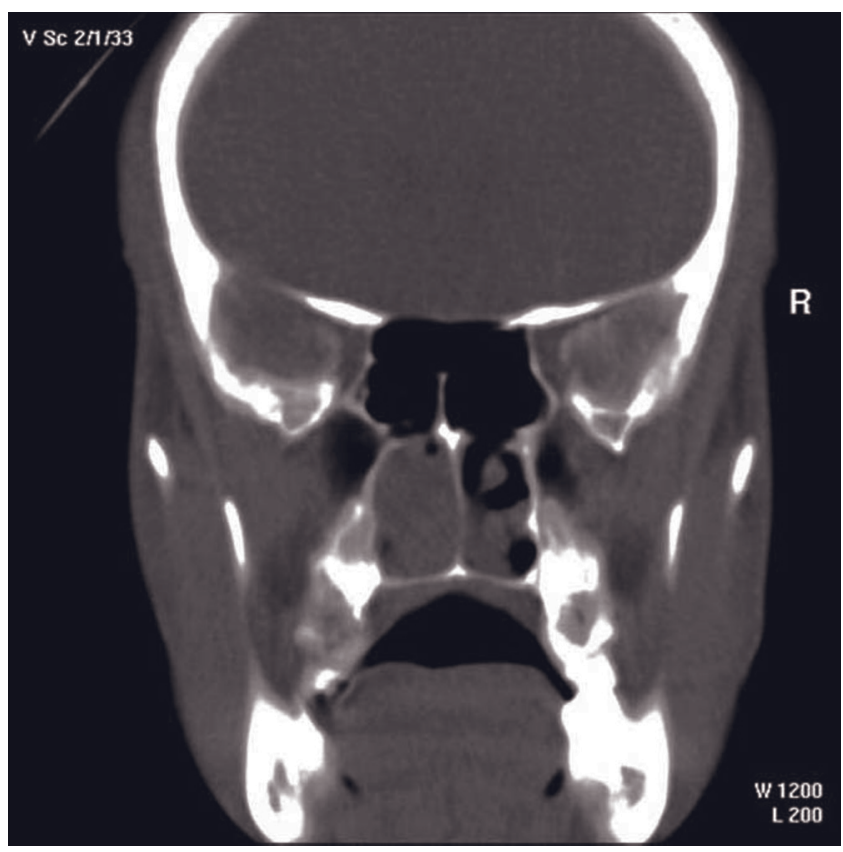

Fig. 1 : CT PNS showing bilateral chronic sinusitis with left sided nasal mass.

present as a friable polypoid vascular mass with the surface studded with tiny white dots from spores beneath the epithelium giving it a characteristic "strawberry-like" appearance and juvenile nasopharyngeal angiofibroma in adolescent males [7].

The treatment of choice is complete surgical excision. When the lesion is large, the differentiation from other hypervascularised lesions may be intriguing. The use of imaging studies like CT scan can give a diagnosis without resorting to biopsy $[1,5]$. The use of nasal endoscopes for both diagnosis as well as surgery is the preferred method of treatment.

In our case the aetiology of the lesion may be hypothesized as microtrauma or chronic irritation due to prolonged use of topical nasal ayurvedic preparations by the individual. This case is reported for its potential for being misdiagnosed and to highlight the advantage of nasal endoscopes in diagnosis and treatment.

\section{Conflicts of Interest}

None identified

\section{References}

1. Puxeddu R, Berlucchi M, Ledda GP, Parodo G, Farina D, Nicolai P. Lobular capillary hemangioma of the nasal cavity: A retrospective study on 40 patients. Am J Rhinol 2006; 20 : 480-4.

2. Jones JE, Nguyen A, Tabaee A. Pyogenic granuloma (pregnancy tumor) of the nasal cavity. A case report. J Reprod Med 2000;45:749-53.

3. Ozcan C, Apa DD, Gorur K. Pediatric lobular capillary

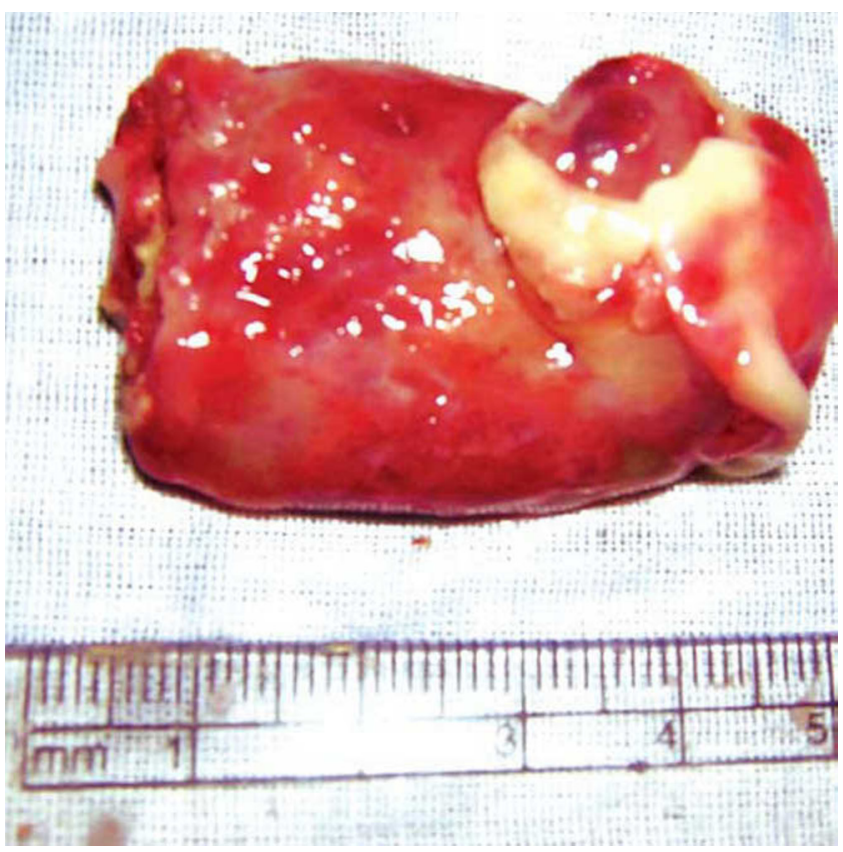

Fig. 2: Gross appearance of the lesion.

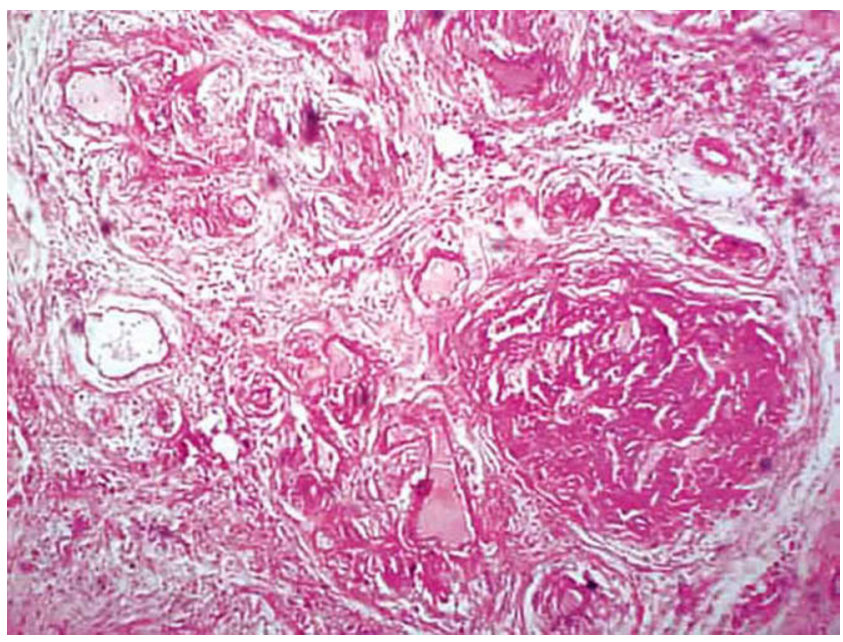

Fig. 3 : Lobular capillary hemangioma showing submucosal vascular proliferation arranged in lobules (H \& E x 100)

hemangioma of the nasal cavity. Eur Arch Otorhinolaryngol 2004;261:449-51.

4. Kapella M, Panosetti E, Rombaux P, Delos M, Weynand B. Lobular capillary haemangioma of the nasal cavity: observation of three specific cases. Acta Otorhinolaryngol Belg 2001; 55 : 241-6.

5. Kurtaran H, Uraldi C, Ark N, Aktas D. Lobular capillary haemangioma of the middle turbinate. Acta Otolaryngol 2006;126:442-4.

6. El-Sayed Y, al-Serhani A. Lobular capillary haemangioma (pyogenic granuloma) of the nose. J Laryngol Otol 1997;111:941-5.

7. Katori H, Tsukuda M. Lobular capillary hemangioma of the nasal cavity in child. Auris Nasus Larynx $2005 ; 32: 185-8$. Epub $2005 ; 23$. 